\title{
Osteoporosis, inflammation and ageing
} Lia Ginaldi*, Maria Cristina Di Benedetto and Massimo De Martinis

Address: Department of Internal Medicine, University of L'Aquila, Italy

Email: Lia Ginaldi* - liaginaldi@alice.it; Maria Cristina Di Benedetto - mdibenedetto@inwind.it; Massimo De Martinis - demartinis@cc.univaq.it

* Corresponding author

Published: 04 November 2005

Immunity \& Ageing 2005, 2:14 doi:10.1186/1742-4933-2-14

This article is available from: http://www.immunityageing.com/content/2/1/14

(c) 2005 Ginaldi et al; licensee BioMed Central Ltd.

This is an Open Access article distributed under the terms of the Creative Commons Attribution License (http://creativecommons.org/licenses/by/2.0), which permits unrestricted use, distribution, and reproduction in any medium, provided the original work is properly cited.
Received: 31 August 2005

Accepted: 04 November 2005

\begin{abstract}
Osteoporosis is a condition characterized by low bone mass and increased bone fragility, putting patients at risk of fractures, which are major causes of morbidity substantially in older people. Osteoporosis is currently attributed to various endocrine, metabolic and mechanical factors. However, emerging clinical and molecular evidence suggests that inflammation also exerts significant influence on bone turnover, inducing osteoporosis. Numerous proinflammatory cytokines have been implicated in the regulation of osteoblasts and osteoclasts, and a shift towards an activated immune profile has been hypothesized as important risk factor. Chronic inflammation and the immune system remodelling characteristic of ageing, as well as of other pathological conditions commonly associated with osteoporosis, may be determinant pathogenetic factors. The present article will review the current perspectives on the interaction between bone and immune system in the elderly, providing an interpretation of osteoporosis in the light of inflamm-ageing.
\end{abstract}

\section{Introduction}

Osteoporosis is a relevant age related disorder, characterized by low bone mass and increased bone fragility putting the patient at risk for fractures [1]. Currently osteoporosis is viewed as a heterogeneous condition which can occur in any age of life and its etiology is attributed to various endocrine, metabolic and mechanical factors (abnormalities of parathyroid hormone and calcitonin secretion, insufficient vitamin $\mathrm{D}$ and calcium intake, postmenopausal hormonal condition, pregnancy, nutritional disorders, immobility and consumption of drugs such as cortisone, among others) [2]. Recently, growing understanding of the bone remodelling process suggests that factors involved in inflammation are linked with those critical for bone physiology and remodelling, supporting the theory that inflammation significantly contributes to the aetiopathogenesis of osteoporosis $[3,4]$.

\section{Is osteoporosis an inflammatory process?}

Clinical observations reveal coincidence of systemic osteoporosis with period of systemic inflammation as well as co-localization of regional osteoporosis with areas of regional inflammation [2]. Different epidemiologic studies report an increase in the risk of developing osteoporosis in various inflammatory conditions [5-8]. Immunological dysfunctions, autoimmune and chronic inflammatory diseases [9], HIV infection [10], hyper-IgE syndrome [11], rheumatoid arthritis [12], haematological diseases, particularly myeloma [13], and inflammatory bowel diseases [14], are associated with osteoporosis. 
Erosions seen in conditions such as gout, osteomyelitis, rheumatoid arthritis, ankylosing spondylitis, and psoriatic arthritis, are typically associated with inflammation in the joints. Pro-osteoclastic cytokines, such as tumour necrosis factor (TNF)- $\alpha$ and interleukin (IL)- 6 , are elevated in these conditions and local cytokine profile is consistent with the cytokines that modulate bone resorption $[15,16]$.

C-reactive protein (CRP) production in the liver is upregulated by IL- 1 , IL- 6 and TNF- $\alpha$, and is regarded as a sensitive marker of systemic inflammation $[17,18]$. An association between circulating high sensitive (hs)CRP level and bone mineral density has been observed in several immune and inflammatory diseases, as well as in healthy individuals, suggesting a relationship between subclinical systemic inflammation and osteoporosis [19].

Rheumatoid arthritis (RA) is a typical example of the link between inflammation and osteoporosis. Bone loss in RA occurs both in the joints and throughout the skeleton as a result of the release of proteinases (metalloproteinases) and proinflammatory cytokines (IL-1, TNF- $\alpha$ ), which are responsible for cartilage and bone destruction. As a result, disease activity is an independent risk factor for osteoporosis in RA [20].

A temporal link between inflammation and osteoporosis also emerges in conditions such as ageing, menopause, pregnancy, transplantation and steroid administration. While nutritional, mechanical and hormonal factors clearly play a role in many of these situations, the concordance of osteoporosis and inflammation is buttressed by emerging molecular evidence of mediating immunological factors [2].

On the other hand, one intriguing aspect of immunosenescence is the increased production of pro-inflammatory cytokines with age and a close link between age-related systemic inflammatory process (inflamm-ageing)[21] and osteoporosis is well documented [22].

\section{A molecular scenario of immune regulated bone loss}

Although osteoporosis is not typically considered an immunological disorder, recent data have indicated overlapping pathways between bone biology and biology of inflammation [23-25]. Certain pro-inflammatory cytokines play potential critical roles both in the normal bone remodelling process and in the pathogenesis of perimenopausal and late-life osteoporosis [26]. For example, interleukin (IL)-6 promotes osteoclast differentiation and activation [27]. This cytokine is involved in the pathogenesis of various metabolic bone diseases, including postmenopausal osteoporosis, Paget's disease and osteoporosis associated with heamtologic malignancies [28]. IL-1 is another potent stimulator of bone resorption [29] that has been linked to the accelerated bone loss seen in idiopathic and postmenopausal osteoporosis [30]. TNF- $\alpha$ is implicated in tumour-induced bone resorption and non-tumour-induced osteopenia [31]. Anti-TNF drugs, currently used in the therapy of several immunological disorders, are also useful in preventing and/or reversing systemic bone loss associated to the disease, as they target both the bone and the inflammatory process [20]. The production of IL- 1, IL- 6 , and/or TNF- $\alpha$ by peripheral blood monocytes has been positively correlated with bone resorption or spinal bone loss in healthy pre- and postmenopausal women [32].

The inflammatory mediator nitric oxide (NO) is also involved in the pathogenesis of osteoporosis. The activation of the inducible NO synthesis (iNOS) pathway by cytokines, such as IL-1 and TNF- $\alpha$, inhibits osteoblast function in vitro and stimulates osteoblast apoptosis [33].

The TNF-family molecule RANKL and its receptor RANK (receptor activator of NFkB ligand) have been specifically implicated in the bone loss in rheumatoid arthritis [34]. They are key regulators of bone remodelling and are essential for the development and activation of osteoclasts. Intriguingly, RANKL/RANK interactions also regulate $\mathrm{T}$ cell/dendritic cell communication, dendritic cell survival and lymphnode formation [35]. Calciotropic factors such as vitamin D3, PGE2, IL-1, IL-11, TNF- $\alpha$ and glucocorticoid induce RANKL expression on osteoblasts [36]. RANKL binding to the RANK expressed on haematopoietic progenitors activates a signal transduction cascade that leads to osteoclast differentiation. Moreover, RANKL stimulates bone resorbing activity in mature osteoclasts via RANK. When RANK is activated, it sends signals into the cells through tumor necrosis factor receptor-associated factors (TRAFs), mainly TRAF6. These RANK associated molecules, through downstream pathways such as NF-kB, JNK/SAPK, p38 and Akt/PKB, regulate bone resorption, activation, survival, and differentiation of osteoclasts and dendritic cells.

Osteoprotegerin (OPG), also known as osteoclastogenesis inhibitory factor, functions as a soluble decoy receptor to RANKL and competes with RANK for RANKL binding. TGF $\beta$ released from bone during active bone resorption has been suggested as a feedback mechanism by upregulating OPG level. Estrogen can enhance OPG production on osteoblasts which is a possible explanation of postmenopausal osteoporosis following estrogen withdrawal [35]. Since the expression of RANKL/RANK can be controlled by sex hormones, it is possible to speculate that this system may control gender specific differences in immunity and could be involved in the higher incidence 
of autoimmune diseases and osteoporosis in women. RANK-L, RANK and OPG therefore configure interesting molecular links between bone remodelling, immunity and inflammation.

\section{The emergence of osteoimmunology}

There exists an intimate interplay between the bone and the immune system which has been termed osteoimmunology [3]. The activity of immune cells affects the balance of bone mineralization and resorption carried out by the opposing actions of osteoblasts and osteoclasts [37].

Dendritic cells, specialized to present antigens, and osteoclasts, specialized to resorb bone, share the same bone marrow precursors of the monocyte lineage and exhibit parallel lifecycles, regulated by a variety of cytokines, transcription factors and inflammatory mediators. Molecules that regulate osteoclastogenesis are key factors in many immunological functions. For example, TRAF6 functions as a molecular bridge spanning adaptive immunity, innate immunity and osteoimmunology [38]. TRAF6deficient mice lack osteoclasts and concomitantly have defects in cytokine production and T cell stimulation [39].

Activated $\mathrm{T}$ cells affect bone physiology producing cytokines that lead to RANKL expression on osteoblasts. Moreover, activated $\mathrm{T}$ cells directly express and produce RANKL that induces osteoclast formation and activation through its specific receptor [28,35]. There are multiple mechanisms and interactions by which cytokines regulate bone resorption. IL- 6 contributes to RANKL upregulation in osteoblastic cells. IL- 1 and TNF- $\alpha$ may not only promote osteoclast generation, but they also appear to stimulate mature osteoclasts to perform more resorption cycles through modulation of RANKL activity. IL-1 is further involved in bone metabolism as an osteoblast activator: osteoblasts secrete RANKL which promotes survival and differentiation of the osteoclast precursors to mature osteoclasts through RANK. IL-1 and IL-6 also directly enhance osteoclast activity by RANKL-independent mechanisms. They may directly extend the lifespan of the osteoclasts by inhibiting osteoclast apoptosis. Both TNF- $\alpha$ and IL-1 inhibit collagen synthesis in osteoblasts and enhance degradation of the extracellular matrix [18]. In inflammatory or autoimmune disease states, activated T cells produce RANKL and pro-inflammatory cytokines, all of which can induce RANKL expression in osteoblasts [40]. However, the constant activity of T cells fighting the universe of antigens to which we are exposed does not usually cause extensive bone loss. Multiple $\mathrm{T}$ cell-derived cytokines, such as IL-12 and IL-18, might be able to interfere with RANK signalling and therefore with osteoclastogenesis and osteoclast functions. A crucial counterregulatory mechanism whereby activated $\mathrm{T}$ cells can inhibit osteoclast development and activation is through the action of the antiviral cytokine interferon (IFN)- $\gamma$. Mechanistically, IFN- $\gamma$ activates the ubiquitin-proteasome pathway within the osteoclasts, resulting in the degradation of TRAF6 [38].

\section{Ageing and osteoporosis: immunological links}

Inflamm-ageing may, at least partially, be a common mechanism for the development of lower bone mass and other age-related disorders $[41,42]$. Senility is in fact notable for acceleration of diseases that are increasingly attributed to inflammation, such as atherosclerosis, Alzheimer's disease and asthma [21,43,44]. Many cytokines, including IL- 6 , TNF- $\alpha$, IL- 1 , are elevated during senescence and play direct roles in the pathogenesis of these diseases [45]. All these cytokines are stimulators of osteoclast activity as well. Associations between atherosclerosis and osteopenia have been well documented $[46,47]$. These findings suggest a potential causal relationship between systemic inflammation that is observed in the elderly and the prevalence of generalized age-related osteoporosis [2]. Moreover, the increased catabolic signal, driven by inflammation also in the absence of clinically diagnosable inflammatory diseases [44], could be able to induce osteoblast apoptosis [48], as well as apoptosis of muscle cells, leading to age-related osteoporosis and sarcopenia respectively.

During ageing, under the influence of the lifelong exposure to chronic antigenic load and oxidative stress, the physiological counter-regulatory process which inhibits bone resorption following $\mathrm{T}$ cell activation is likely impaired. This would contribute, together with the agerelated systemic low-grade inflammation, to the increasing incidence of osteoporosis during senescence.

Osteoporosis, as well as other age-related disorders, has a strong genetic component and the rate extent of bone loss during senescence varies widely between individuals. It is tempting to postulate that this may be in part due to individual differences in cytokine activity. In support of this hypothesis it has been demonstrated that certain IL-6 polymorphisms are able to influence the risk of osteoporosis in postmenopausal women [49]. Similarly, IL-1 $\beta$ and IL-1 receptor antagonist (IL-1Ra) gene polymorphisms are associated with reduced bone mineral density and predispose women to osteoporosis at the lumbar spine [50].

Moreover, also the sex hormonal decline which accompanies ageing contributes to the pathogenesis of senile osteoporosis through immunologically mediated mechanisms. It has been postulated that estrogens exert their effect on bone not only by direct action per se, but also by inhibiting IL-6 gene expression. A similar relationship between androgen and IL- 6 gene expression also exists [51]. The decline in ovarian function is associated 
with decreased OPG production and spontaneous increases in proinflammatory and pro-osteoclastic cytokines such as IL- 6 , TNF- $\alpha$, and IL-1 [32,52,53].

\section{Osteoporosis within an evolutionary perspective}

During evolution of multi-cellular organisms, the increasing complexity of emerging systemic functions, such as inflammation, may have led to a widening range of demand for key minerals such as calcium and phosphate and storage functions may have evolved to provide mineral reservoirs [2]. Moreover, calcium is an important component of milk and its transport from mother to the fetus and neonate is a vital process to preserve species. Intriguingly, RANKL and RANK also play essential roles in the formation of a lactating mammary gland in pregnancy. This could partly contribute to both the immune remodelling and the accelerated bone loss during pregnancy and lactating [35]. Bone can thus be viewed as a mobilizable reservoir of calcium and phosphate as salts. Over time, the regulation of bone turnover was probably optimized evolutionarily to address the combined metabolic and structural demands of the host.

In this perspective osteoporosis may reflect a state of disequilibrium between structural demand for calcium and phosphate and their biologic demand during metabolically active states such as inflammation. Inflammation is the leading force driving immunosenescence and the chronic low-grade inflammatory state characteristic of ageing represents the predisposing substrate on which osteoporosis, as well as other age-related diseases, might emerge [21,54].

The lack of evolutionary selective pressure post-reproduction may have further exacerbated this disequilibrium in modern times and many biologic functions acquired during evolution have become maladaptive. Presently, in most developed countries, the human lifespan is greatly increased, and many individuals are living into postreproductive senescence, an evolutionarily naive life epoch. Obesity, diabetes, Alzheimer's disease and atherosclerosis are examples of diseases of modernity that are attributable to modern living circumstances or that are unmasked during senility, and also the emergence of osteoporosis as a modern disease may be an example of this phenomenon $[2,21,44]$.

\section{References}

I. Delmas PD: Treatment of postmenopausal osteoporosis. Lancet 2002, 359:2018-26.

2. Yun AJ, Lee PY: Maladaptation of the link between inflammation and bone turnover may be a key determinant of osteoporosis. Med Hypotheses 2004, 63:532-537.

3. Arron JR, Choi Y: Bone versus immune system. Nature 2000, 408:535-6.

4. Lorenzo J: Interactions between immune and bone cells: new insights with many remaining questions. J Clin Invest 2000, 106:749-52.
5. Mitra D, Elvins DM, Speden DJ, Collins AJ: The prevalence of vertebral fractures in mild ankylosing spondylitis and their relationship to bone mineral density. Rheumatology 2000, 39:85-9.

6. Haugeberg G, Lodder MC, Lems WF, Uhlig T, Orstavik RE, Dijkmans $B A$, Kvien TK, Woolf AD: Hand cortical bone mass and its associations with radiographic joint damage and fractures in 50 70 year old female patients with rheumatoid arthritis: cross sectional Oslo-Truro-Amsterdam (OSTRA) collaborative study. Ann Rheum Dis 2004, 63:| $33 \mid-4$.

7. Bultink IE, Lems WF, Kostense PJ, Dijkmans BA, Voskuyl AE: Prevalence of and risk factors for low bone mineral density and vertebral fractures in patients with systemic lupus erythematosus. Arthritis Rheum 2005, 52:2044-50.

8. Mikuls TR, Saag KG, Curtis J, Bridges SL Jr, Alarcon GS, Westfall AO, Lim SS, Smith EA, Jonas BL, Moreland LW, CLEAR investigators: Prevalence of osteoporosis and osteopenia among African Americans with early rheumatoid arthritis: the impact of ethnic-specific normative data. I Natl Med Assoc 2005, 97: I 155-60

9. Walsh NC, Gravallese EM: Bone loss in inflammatory arthritis: mechanisms and treatment strategies. Curr Opin Rheumatol 2004, 16:419-27.

10. Annapoorna N, Rao GV, Reddy NS, Rambabu P, Rao KR: An increased risk of osteoporosis during acquired immunodeficiency syndrome. Int J Med Sci 2004, I: I 52-I 64.

II. Leung DY, Geha RS: Clinical and immunologic aspects of the hyperimmunoglobulin E syndrome. Hematol Oncol Clin North Am 1988, 2:81-100.

12. Jensen T, Klarlund M, Hansen M, Jensen KE, Skjodt H, Hydlldstrup L: Connective tissue metabolism in patients with unclassified polyarthritis and early rheumatoid arthritis. Relationship to disease activity, bone mineral density, and radiographyc outcome. J Rheumatol 2004, 3 I: I698-I708.

13. Abrahamsen B, Andersen I, Christensen SS, Skov Madsen J, Brixen K: Utility of testing for monoclonal bands in serum of patients with suspected osteoporosis: retrospective, cross sectional study. BMJ 2005, 330:818.

14. Moschen AR, Kaser A, Enrich B, Ludwiczek O, Gabriel M, Obrist P, Wolf AM, Tilg $H$ : The RANKL/OPG system is activated in inflammatory bowel disease and relates to the state of bone loss. Gut 2005, 54:479-87.

15. Ishihara K, Hirano T: IL-6 in autoimmune disease and chronic inflammatory proliferative disease. Cytokine Growth Factor Rev 2002, I 3:357-68

16. Moschen AR, Kaser A, Enrich B, Ludwiczek O, Gabriel M, Obrist P, Wolf $A M$, Tilg $H$ : RANKL/OPG system is activated in inflammatory bowel disease and relates to the state of bone loss. Gut 2005, 54:479-87.

17. Koh JM, Kang YH, Jung CH, Bae S, Kim DJ, Chung YE, Kim GS: Higher circulating hsCRP levels are associated with lower bone mineral density in healthy pre-and postmenopausal women: evidence for a link between systemic inflammation and osteoporosis. Osteoporosis Int 2005, doi:. 10.1007/s00198-005I840-5

18. Muller B: Cytokine imbalance in non immunological chronic disease. Cytokine 2002, I 8:334-339.

19. Ganesan K, Teklehaimanot S, Tran TH, Asuncion M, Norris K: Relationship of $\mathrm{C}$-reactive protein and bone mineral density in community-dwelling elderly females. I Natl Med Assoc 2005, 97:329-33.

20. Saidenberg-Kermanac'h N, Cohen-Solal M, Bessis N, De Vernejoul MC, Boissier MC: Role for osteoprotegerin in rheumatoid inflammation. Joint Bone Spine 2004, 71 :9-3I.

21. Franceschi $C$, Bonafè $M$, Valensin S, Olivieri F, De Luca M, Ottaviani E, De Benedictis G: Inflamm-ageing. An evolutionary perspective on immunosenescence. Ann N Y Acad Sci 2000, 908:244-54.

22. Kiecolt-Glaser JK, Preacher KJ, MacCallum RC, Atkinson C, Malarkey WB, Glaser R: Chronic stress and age-related increases in the proinflammatory cytokine IL-6. Proc Natl Acad Sci USA 2003, 100:9090-5.

23. Goldring SR: Inflammatory mediators as essential elements in bone remodeling. Calcif Tissue Int 2003, 73:97-100.

24. Siggelkow H, Eidner T, Lehmann G, Viereck V, Raddarz D, Munzel U, Hein G, Hufner M: Cytokines, osteoprotegerin, and RANKL in vitro and histomorphometric indices of bone turnover in 
patients with different bone diseases. J Bone Miner Res 2003, 18:529-38.

25. Pfeilschifter J: Role of cytokines in postmenopausal bone loss. Curr Osteoporos Rep 2003, I:53-8.

26. Manolagas SC, Jilka RL: Bone marrow, cytokines, and bone remodeling. Emerging insights into the pathophysiology of osteoporosis. N Engl J Med 1995, 332:305-II.

27. Manolagas SC: Birth and death of bone cells: basic regulatory mechanisms and implications for the pathogenesis and treatment of osteoporosis. Endocr Rev 2000, 21:115-137.

28. Takayanagi H, Ogasawara K, Hida S, Chiba T, Murata S, Sato K, Takaoka A, Yokochi T, Oda H, Tanaka K, Nakamura K, Taniguchi T: Tcell-mediated regulation of osteoclastogenesis by signalling cross-talk between RANKL and IFN-gamma. Nature 2000, 408:600-5.

29. Wei S, Kitaura H, Zhou P, Ross FP, Teitelbaum SL: IL-I mediates TNF-induced osteoclastogenesis. J Clin Invest 2005, I I 5:282-90.

30. Pacifici R, Rifas L, McCracken R, Vered I, McMurtry C, Avioli LV, Peck WA: Ovarian steroid treatment blocks a postmenopausal increase in blood monocyte interleukin I release. Proc Natl Acad Sci USA 1989, 86:2398-2402.

31. Moffett SP, Zmuda JM, Oakley JI, Beck TJ, Cauley JA, Stone KL, Lui LY, Ensrud KE, Hillier TA, Hochberg MC, Morin P, Peltz G, Greene D, Cummings SR: Tumor necrosis factor-alpha polymorphism, bone strength phenotypes, and the risk of fracture in older women. J Clin Endocrinol Metab 2005, 90:349I-7.

32. Scheidt-Nave C, Bismar H, Leidig-Bruckner G, Woitge H, Seibel MJ, Ziegler R, Pfeilschifter J: Serum interleukin 6 is a major predictor of bone loss in women specific to the first decade post menopause. J Clin Endocrinol Metab 200I, 86:2032-42.

33. Armour KJ, Armour KE, van't Hof RJ, Reid DM, Wei XQ, Liew FY, Ralston SH: Activation of the inducible nitric oxide synthase pathway contributes to inflammation-induced osteoporosis by suppressing bone formation and causing osteoblast apoptosis. Arthritis Rheum 200I, 44:2790-6.

34. Romas E, Gillespie MT, Martin TJ: Involvement of receptor activator of NFkappaB ligand and tumor necrosis factor-alpha in bone destruction in rheumatoid arthritis. Bone 2002, 30:340-6.

35. Theill LE, Boyle WJ, Penninger JM: KANK-L and RANK: T cells, bone loss, and mammalian evolution. Annu Rev Immunol 2002, 20:795-823.

36. Eghbali-Fatourechi G, Khosla S, Sanyal A, Boyle WJ, Lacey DL, Riggs $B L$ : Role of RANK ligand in mediating increased bone resorption in early postmenopausal women. J Clin Invest 2003 I I I:I22I-30.

37. Teitelbaum SL: Osteoclasts, integrins, and osteoporosis. J Bone Miner Metab 2000, 18:344-9.

38. Wu H, Arron JR: TRAF6, a molecular bridge spanning adaptive immunity, innate immunity and osteoimmunology. BioEssays 2003, 25: 1096-II05.

39. Lomaga MA, Yeh WC, Sarosi I, Duncan GS, Furlonger C, Ho A, Morony S, Capparelli C, Van G, Kaufman S, van der Heiden A, Itie A, Wakeham A, Khoo W, Sasaki T, Cao Z, Penninger JM, Paige C, Lacey DL, Dunstan CR, Boyle WJ, Goeddel DV, Mak TW: TRAF6 deficiency results in osteopetrosis and defective interleukin-I, CD40, and LPS signaling. Genes Dev 1999, 13:1015-24.

40. Hofbauer LC, Lacey DL, Dunstan CR, Spelsberg TC, Riggs BL, Khosla $S$ : Interleukin-I beta and tumor necrosis factor-alpha, but not interleukin-6, stimulate osteoprotegerin ligand gene expression in human osteoblastic cells. Bone 1999, 25:255-9.

41. Wallin R, Wajih N, Greenwood GT, Sane DC: Arterial calcification: a review of mechanisms, animal models, and the prospects for therapy. Med Res Rev 2001, 21:274-301.

42. Hirose K, Tomiyama H, Okazaki R, Arai T, Koji Y, Zaydun G, Hori S, Yamashina A: Increased pulse wavevelocity associated with reduced calcaneal quantitative osteo-sono index: possible relationship between atherosclerosis and osteopenia. J Clin Endocrinol Metab 2003, 88:2573-2578.

43. Bruunsgaard $\mathrm{H}$, Pedersen BK: Age-related inflammatory cytokines and disease. Immunol Allergy Clin North Am 2003 23:15-39.

44. Ginaldi L, De Martinis M, Monti D, Franceschi C: Chronic antigenic load and apoptosis in immunosenescence. Trends Immunol 2005, 26:79-84.
45. Bruunsgaard $\mathrm{H}$ : Effects of tumor necrosis factor-alpha and interleukin-6 in elderly populations. Eur Cytokine Netw 2002, |3:389-39|

46. Hak AE, Pols HA, van Hemert AM, Hofman A, Witteman JC: Progression of aortic calcification is associated with metacarpal bone loss during menopause: a population-based longitudinal study. Arterioscler Thromb Vasc Biol 2000, 20:|926-1931.

47. Jorgensen L, Engstad T, Jacobsen BK: Bone mineral density in acute stroke patients: low bone mineral density may predict first stroke in women. Stroke 200I, 32:47-5I.

48. Roubenoff $\mathrm{R}$ : Catabolism of aging: is it an inflammatory process? Curr Opin Clin Nutr Metab Care 2003, 6:295-299.

49. Ferrari SL, Ahn-Luong L, Garnero P, Humphries SE, Greenspan SL: Two promoter polymorphisms regulating interleukin-6 gene expression are associated with circulating levels of C-reactive protein and markers of bone resorption in postmenopausal women. J Clin Endocrinol Metab 2003, 88:255-259.

50. Chen HY, Chen WC, Wu MC, Tsai FJ, Lin CC: Interleukin-Ibeta and interleukin-I receptor antagonist gene polymorphism in postmenopausal women: correlation to bone mineral density and susceptibility to osteoporosis. Maturitas 2002, 44:49-54.

51. Liu H, Liu K, Bodenner DL: Estrogen receptor inhibits interleukin-6 gene expression by disruption of nuclear factor kappa B transactivation. Cytokine 2005, 3 I:25I-257.

52. Pfeilschifter J, Koditz R, Pfohl M, Schatz $\mathrm{H}$ : Changes in proinflammatory cytokine activity after menopause. Endocr Rev 2002, 23:90-II9.

53. Ershler W, Harman SM, Keller ET: Immunologic aspects of osteoporosis. Dev Comp Immunol 1 997, 2 I :487-499.

54. De Martinis M, Franceschi C, Monti D, Ginaldi L: Inflamm-ageing and lifelong antigenic load as major determinants of ageing rate and longevity. FEBS Lett 2005, 579:2035-2039.
Publish with Bio Med Central and every scientist can read your work free of charge

"BioMed Central will be the most significant development for disseminating the results of biomedical research in our lifetime. "

Sir Paul Nurse, Cancer Research UK

Your research papers will be:

- available free of charge to the entire biomedical community

- peer reviewed and published immediately upon acceptance

- cited in PubMed and archived on PubMed Central

- yours - you keep the copyright
BioMedcentral 